\title{
Ensino-Ação: Uma Experiência de Aprendizado por Meio da Extensão Universitária
}

\author{
Vivian Lara Silva ${ }^{1 *}$, Fausto Makishi ${ }^{2}$ \\ ${ }^{1}$ Faculdade de Zootecnia e Engenharia de Alimentos da Universidade de São Paulo \\ 2Instituto de Ciências Agrárias da Universidade Federal de Minas Gerais
}

* Autora para correspondência: vivianlara@usp.br

\section{RESUMO}

Este texto relata uma experiência metodológica pioneira que vem sendo desenvolvida nos últimos dez anos na disciplina de Gestão Industrial, oferecida pelo curso de Engenharia e Alimentos da Faculdade de Zootecnia e Engenharia de Alimentos da Universidade de São Paulo (FZEA/USP). A iniciativa inova ao incorporar a extensão universitária, via empreendedorismo social, à metodologia de Aprendizagem Baseada em Problemas, ou Problem-Based Learning (PBL). O trabalho universitário junto à comunidade local motiva e enseja a aplicação de conceitos abordados em sala de aula, com importantes resultados em termos de fomento ao conhecimento, habilidade e atitude dos discentes. Ao mesmo tempo, reforça valores e aproxima universidade, empresa e sociedade. Mais do que prática e experiência exitosas restritas ao curso e à instituição, os resultados sugerem ser o método de ensino-ação por meio da extensão universitária potencialmente valioso ao incremento que se faz necessário à formação superior no Brasil.

Palavras-Chave: Metodologia de Ensino-Aprendizado; Responsabilidade Social Universitária; Interação Universidade-Empresa.

\begin{abstract}
This paper reports a pioneering methodological experience that has been developed in the last ten years in the Industrial Management course offered by the Food Engineering and Engineering degree at the Animal Science and Food Engineering School of the University of São Paulo (FZEA/USP). The initiative innovates by incorporating university extension, through social entrepreneurship, to the Problem-Based Learning (PBL) methodology. The university work with the local community motivates and encourages the application of concepts addressed in the classroom, with important results in terms of promoting the knowledge, ability and attitude of the students. At the same time, it reinforces values and approaches university, business and society. More than successful practice and experience restricted to the course and to the institution, the results suggest that the teaching-action method through the university extension is potentially valuable to the increment, which is necessary for the higher education in Brazil.
\end{abstract}

Keywords: Teaching-Learning Methodology; University Social Responsibility; University-Industry Interaction.

\section{Introdução}

Mudanças no ambiente institucional e competitivo sempre ocasionaram reflexos diretos nas atividades econômicas, sociais e políticas. Nunca, porém, isso se deu com a complexidade e o ritmo acelerado observados nos últimos tempos, especialmente em face do desenvolvimento tecnológico nas mais diferentes áreas do conhecimento e do repensar das formas em que modernamente a sociedade se organiza, regula e atende suas necessidades.
Diante desse cenário, formar profissionais aptos a ingressarem no mercado de trabalho e atenderem aos anseios da sociedade já seria, por si, um grande desafio, sobretudo, e não apenas, diante da necessidade de se desenvolverem ferramentas de aprendizado adequadas ao contexto geracional. Não há como deixar de reconhecer, por exemplo, a existência do fosso que separa a formação e os métodos de atuação que consagraram grande parte dos nossos docentes universitários e o público 
discente que hoje frequenta nossas faculdades.

Particularmente instigados por esse contexto, os autores do presente trabalho procuram retratar a experiência de ensino que vem ocorrendo na disciplina de Gestão Industrial oferecida no curso de Engenharia e Alimentos da Faculdade de Zootecnia e Engenharia de Alimentos da Universidade de São Paulo (FZEA/USP). A iniciativa dos autores se fundamenta na metodologia de Aprendizagem Baseada em Problemas, ou Problem-Based Learning (PBL) (BARROWS, 1986; BOUD \& FELETTI, 1998; DUCH, GROH \& ALLEN, 2001), abordagem originada na área da saúde e que cada vez mais ganha espaço no ensino universitário em geral (GILBERT \& FOSTER, 1997; ROBERTO, 2005; PEREIRA et al., 2007; ESGRIVÃO FILHO, RIBEIRO, 2009; DALY et al. 2012; FREZATTI \& MARTINS, 2016).

Segundo Escrivão Filho e Ribeiro (2009), uma característica-chave da PBL é que a identificação do problema, ou situação problema, sempre precede a apresentação dos conceitos necessários para sua solução. Essa é, possivelmente, a principal contribuição da PBL, a motivação e valorização da informação.

É preciso notar que a globalização e a evolução nos meios de comunicação são características marcantes de um contexto em que a informação é acessível e excessiva. A constante avalanche de conceitos despejados sobre as pessoas tende a fomentar a criação de filtros, sendo que o inútil não é absorvido.

Procurando reverter (ou minimizar) esse efeito, pesquisas educacionais, especialmente na área da psicologia cognitiva, indicam que o trabalho dos alunos, atuando particularmente em grupos e atentos às demandas do cotidiano, favorece a aprendizagem (ESCRIVÃO FILHO \& RIBEIRO, 2009). A premissa é que, para as informações se tornarem conhecimento, faz-se necessário ativar conceitos e estruturas cognitivas existentes a respeito do assunto. De forma que, mais do que exercitar os conhecimentos, parece estratégico criar mecanismos de valorização das informações, com base em sua utilidade. Roberto (2005) identifica ainda que a aprendizagem é aprimorada pela interação social, sugerindo a potencialização do processo quando desenvolvido em grupos de alunos.

Partindo dos princípios do PBL, o caso específico da experiência desenvolvida pelos autores do presente artigo na FZEA/USP reserva inovações adicionais na medida em que valoriza a extensão universitária, incorporando a ela o ferramental metodológico de ensino baseado em problemas.

A característica central da extensão universitária - resolver um problema imediato - cria impactos igualmente imediatos e sensíveis, motivando os alunos. A extensão leva ao mundo real e abre portas ao se alinhar à responsabilidade social corporativa, aproximando universidade, empresa e sociedade. Esse poderoso tripé representa a base da metodologia retratada na experiência aqui relatada e apresentada em detalhes na seção que segue.

Adicionalmente, a experiência de ensino-ação desenvolvida na FZEA/USP contribui para o desenvolvimento de habilidades normalmente não abordadas em conteúdos curriculares de escolas de engenharia, conforme observam Smith (2005) e Hsieh e Knight (2008). As chamadas soft-skills compreendem um conjunto de habilidades, também associadas à inteligência emocional, necessárias e valorizadas para desenvolver atividades profissionais, incluindo: comunicação verbal, poder de persuasão, oratória, assertividade, liderança, atitude positiva, trabalho em equipe e criatividade, entre outras.

\section{A Metodologia de Aprendizado por meio da Extensão Universitária}

Vale notar que, ao contrário das escolas de business e economia, o conteúdo programático proposto na disciplina de Gestão Industrial foge da ortodoxa formação de engenharia de alimentos no Brasil, centrada em tecnologia de processamento e conservação. Esse contexto inspirou o pensar em inovações metodológicas que fomentassem o processo de aprendizado e de solidificação dos conceitos tratados na disciplina em questão. O que, por sua vez, culminou em estratégias de oportuna imersão dos discentes junto "ao mundo 
real", a partir da idealização de uma experiência que rompia com a zona de conforto dos alunos, instigando-os a atuarem e lidarem, segundo o jargão da própria engenharia de alimentos, em uma atmosfera não controlada. $\mathrm{O}$ resultado foi a concepção de uma fórmula que há dez anos vem sendo desenvolvida na FZEA/USP, cuja essência é resumida na Figura 1.

A metodologia segue a lógica de gestão de projetos aplicada a empreendedorismo social, com fins, prazos e métricas de acompanhamento bem definidos. Assim, a iniciativa de impacto socioambiental é planejada e posteriormente executada pelos discentes matriculados na disciplina, ao longo de quinze semanas. Em seu âmbito maior, os projetos devem contemplar o propósito de "sustentabilidade" das ações, no que se refere ao desafio adicional de as ações executadas serem perpetuadas após o término do semestre letivo.

Segundo a fundamentação de PBL, a motivação para o aprendizado se dá nas fases de planejamento, execução e controle das atividades relacionadas a cada um dos projetos, em função dos diferentes conflitos encontrados (de relacionamento, curto prazo, custos, processos burocráticos, além de fatores cognitivos como apropriação e percepção de benefícios por parte dos beneficiados etc.). Como suporte, entram as ferramentas e os conceitos teóricos propostos pelo curso, como ciclo PDCA (Planning, Doing, Controling e Acting), gestão de conflito, marketing, gestão da produção, análise de custos e gestão de recursos humanos.

Na prática, isso acontece da seguinte forma. No início do semestre letivo, nas três primeiras semanas do curso, os discentes (em equipes de até cinco integrantes) são convidados a estudar estratégias empresariais materializadas nos valores e missões de empresas, particularmente de alimentos, mas não restritas a esse setor econômico. Tais empresas são, então, reconhecidas como "inspiradoras". A partir disso, as equipes devem identificar uma oportunidade de ação socioambiental que se alinhe às empresas estudadas.

Da identificação dessa oportunidade, a primeira fase da metodologia contempla a formalização de um projeto de responsabilidade social corporativa a ser apresentada e discutida junto às empresas inspiradoras, com o objetivo de selar parceria e apoio para a condução das ações idealizadas. $\mathrm{O}$ apoio das empresas se materializa em duas principais frentes: possibilidade de vincular a marca organizacional em materiais e em atividades desenvolvidas pelos grupos; doação de materiais, equipamentos e insumos. Por fim, a parceria deve contemplar a imersão (de um a dois dias) dos integrantes do projeto nas empresas, justamente com o intuito de vivenciar a dinâmica organizacional em geral e a das áreas relacionadas à gestão industrial em especial.

Ainda nessa primeira fase do projeto - do planejamento das propostas -, os alunos devem buscar articulação com outros professores e pesquisadores, assumindo status de tutores, referindo-

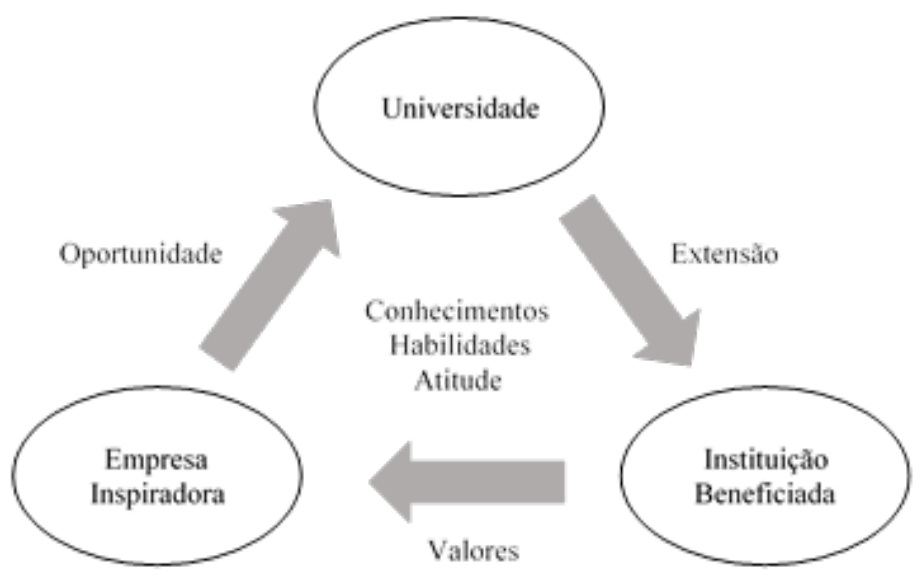

Figura 1 - Esquema da Aprendizagem por meio da Extensão Universitária. Fonte: Autores desta pesquisa. 
se a colegas de áreas específicas da engenharia de alimentos ou mesmo subjacentes à formação, beneficiando-se das demais formações oferecidas pela FZEA/USP.

Além disso, os discentes assumem o desafio de estreitar relacionamento com as instituições a serem beneficiadas, formulando dinâmicas e ações que sejam coerentes com suas restrições e interesses.

Uma vez concebidos o projeto e a articulação com os seus stakeholders, o projeto de ação socioambiental passa a ser executado junto à comunidade, com o intuito de beneficiar instituições da cidade. Esse é o direcionador das oito semanas que se seguem.

Encerrado esse segundo ciclo, os alunos passam para a mensuração, análise e discussão dos impactos gerados, o que se dá ao longo de no máximo três semanas, quando, então, se chega ao término do semestre.

Em paralelo a essa trama de ações, o curso de gestão industrial é conduzido semanalmente. A exposição dos alunos a situações reais do ambiente institucional e corporativo que devem ser solucionadas para o desenrolar dos projetos representa uma das principais fontes de inspiração ao aprendizado, ocasião em que os alunos buscam, na aplicação dos conhecimentos acumulados em gestão de projetos e na lógica de avaliações continuadas das metas versus resultados, soluções aplicadas a cada situação que visem à eficiência das ações.

Ao término das quinze semanas, tem-se então o "Workshop de Prática da Responsabilidade Social na Formação em Engenharia de Alimentos: Aprendizagem com Extensão no Ensino de Gestão Industrial", fórmula que se consagrou a partir de 2013. Nesse workshop, os discentes passam pela experiência de apresentar para uma comissão interdisciplinar e interinstitucional (incluindo representantes do meio corporativo, a exemplo de diretores e gestores de empresas dos mais diferentes ramos) os impactos gerados pelos respectivos projetos. Essa comissão elege os melhores projetos com base em três categorias principais: melhor projeto, melhor apresentação e projeto com maior potencial de continuidade.

\section{Considerações Finais}

Os resultados na aplicação da metodologia de aprendizado por meio da extensão revelaram-se extremamente frutíferos, com ganhos potenciais e auspiciosos para um futuro bem próximo. Do desafio inicial de sensibilizar e incentivar os discentes a se permitirem adentrar e explorar um universo maior do que a visão ortodoxa possibilita, decorre uma experiência que vem evidenciando, ano a ano, motivação e expectativa crescentes dos alunos por discussões aprofundadas na área de gestão e pela execução de projetos de empreendedorismo social. São dignos de destaque projetos que a cada ano se superam pelos resultados e impactos junto à comunidade, alguns dos quais atendendo plenamente ao desafio de as propostas se perpetuarem no tempo.

Estes são alguns elementos sugestivos para que o anseio maior da concepção da inovação metodológica fosse atendido: a amarração do aprendizado por meio da extensão, que vem apresentando importantes resultados em termos de incentivo ao conhecimento, habilidade e atitude dos discentes. De fato, o êxito da experiência nesses primeiros dez anos evidencia resultados positivos e significativos, a exemplo dos descritos a seguir.

(i) Aprimoramento do conhecimento em gestão industrial no que se refere à introdução e sensibilização dos discentes junto aos universos de planejamento e controle da produção, administração de marketing, análise econômica e gestão sustentável de projetos.

(ii) Desenvolvimento de (novas) habilidades, estimulando os discentes a saírem da zona de conforto e lidarem com uma atmosfera não controlada, fomentando capacidades de liderança, negociação, comunicação, persuasão, carisma, gestão do tempo e superação de obstáculos.

(iii) Fomento de (novas) atitudes, contribuindo para o desenvolvimento contínuo de pessoas comprometidas com um mundo sustentável.

Muitos dos jovens universitários que ajudaram a fazer a história ao longo desses dez anos 
já apresentam carreiras sólidas no mercado de trabalho, assumindo postos de liderança nas mais diferentes áreas e setores. Esses líderes são convidados a participar das atividades da disciplina, proferindo palestras e ainda integrando a banca examinadora dos projetos. Participações que representam mais um elemento importante na motivação dos discentes.

Finalizando, a extensão universitária tem exercido um papel de fundamental importância no tocante à aproximação entre as instituições de ensino e pesquisa e a sociedade na qual elas se inserem. Cabe lembrar que a educação superior, infelizmente, ainda está longe do interesse e do cotidiano da população brasileira, justamente ela que é responsável por grande parte dos recursos que sustentam as universidades públicas. Por isso, dentre os resultados positivos e imediatos da iniciativa aqui relatada, pode-se destacar a legitimação do trabalho universitário junto à comunidade local.

\section{Referências Bibliográficas}

BARROWS, H. S. "A Taxonomy of Problem-Based Learning Methods". Medical Education, vol. 20, n. 6, pp. 481-486, 1986.

BOUD, D. \& FELETTI, G. (eds.). "The Challenge of Problem-Based Learning". Psychology Press, 1998.

DALY, P. S.; WHITE, M. M.; ZISK, D. S. \& CAVAZOS, D. E. "Problem-Based Teaching in International Management: A Political/Economic Risk Assessment Exercise". Fournal of Teaching in International Business, vol. 23, n. 4, pp. 260-276, 2012.
DUCH, B.J.; GROH, S. E. \& ALLEN, D. E. (eds.). "The Power of Problem-Based Learning: A Practical 'How To' For Teaching Undergraduate Courses In Any Discipline". Stylus Publishing, LLC., 2001.

ESCRIVÃO FILHO, E. \& RIBEIRO, L. R. C. "Aprendendo com PBL - Aprendizagem Baseada em Problemas: Relato de Uma Experiência em Cursos de Engenharia da EESC-USP". Revista Minerva: Pesquisa e Tecnologia, vol. 6, n. 1, pp. 23-30, 2009.

FREZATTI, F. \& MARTINS, D. B. "PBL ou PBLs: a Customização do Mecanismo de Aprendizagem Baseada em Problemas na Educação Contábil". Rev. Grad. USP, vol. 1, n. 1, 2016.

GILBERT, A. \& FOSTER, S. F. "Experiences with Problem-Based Learning in Business and Management". In: BOUD, D. \& FELETTI, G. (eds.). The Challenge of Problem-Based Learning. London: Kogan Page, 1997, pp. 244-252.

HSIEH, C. \& KNIGHT, L. "Problem-Based Learning for Engineering Students: An Evidence-Based Comparative Study". The Fournal of Academic Librarianship, vol. 34, n. 1, pp. 25-30, 2008.

PEREIRA, C. F.; AFONSO, R. A.; SANTOS, M. J.; ARAÚJO, C. A. L. \& NOGUEIRA, M. "Aprendizagem Baseada em Problemas (ABP): Uma Proposta Inovadora para os Cursos de Engenharia". Simpósio de Engenharia de Produção - XIV Simpep 2007, 2007.

RIBEIRO, A. L. R. C. "Aprendizagem Baseada em Problemas (PBL) na Educação em Engenharia". Revista de Ensino de Engenharia, vol. 27, n. 2, pp. 23-32, 2009.

ROBERTO, L. A Aprendizagem Baseada em Problemas (PBL): uma Implementaşão na Educaşão em Engenharia na Voz dos Atores. Tese (Doutorado em Educação), Universidade Federal de São Carlos, 2005.

SMITH, K. A. et al. "Pedagogies of Engagement: Classroom-Based Practices". Fournal of Engineering Education, vol. 94, n. 1, pp. 87-101, 2005. 